Deber d. Vorkommen v. Scorodosma foetidum im turkestan, Gebiete. 185

durch die Zersetzung, welche die Traube wie jeder Organismus zeigt, der den Culminationspunkt seiner Entwickelung überschritten; die Mitwirkung der Schimmelpilze wird dabei als von bedeutendem Einflusse anzusehen sein. (Aus d. Natur. 1870.).

R.

\title{
Ueber das Vorkommen von Scorodosma foetidum im turkestanischen Geblete.
}

Ein kleiner Theil der sogenannten Hungersteppe liegt zwischen dem 40-41 Breiten - und dem 371/2 - 381/8 Längengrade, südwestlich von Tuschkent zwischen dem SirDarja und dem Gebirge Kura-tau und erstreckt sich nach Nordwesten, fast bis zum Aralsee. Diese, im Süden und Westen vom Gebirge, im Osten vom Flusse nmgrenzte Strecke zeichnet sich durch einen sebr festen, kalk- und salzhaltigen Boden aus, der erst weiter nach dem Aralsee hin sandig wird. Ohngefähr 15-25 Werst, sowohl vom Flusse, wie auch vom Gebirge entfernt, findet man nach $L$ e u tner's Angabe eine $2^{1 / 2}-3$ Fuss hohe Pflanze mit mächtigem Stengel, welche sich durch ihren Habitus, schon aus der Ferne, als Umbellifere kennzeichnet. Je weiter man zum Mittelpunkt der Steppe kommt, desto hänfiger wird diese Pflanze, bis ohngefähr zur Poststation an dem Brunnen Musarabat, wo sie die ganze Ebene, so weit das Auge reicht, bedeckt. Es ist Scorodosma foetidum Bunge.

Wenn im Frühiahr der Boden von den Winterniederschlägen noch feucht ist, entwickelt sich der oberirdische Theil von Scorodosma foetidum, erreicht in sehr kurzer Zeit seine volle Höbe und blüht gewöhnlich $\mathrm{zu}$ Anfang Mai, wo sie dann die ganze Gegend mit ihrem widerlichen Duft erfüllt. Nachdem später durch die ungeheure Sonnenhitze der Boden ausgetrocknet ist, vertrocknet auch allmählig die Pflanze, der Geruch derselben verschwindet und nur der Stengel mit den Samen bleibt bis zum Herbst stehen, wo derselbe vom Winde gleich oberhalb der Wurzel abgebrochen wird und beim Weiterwehen die Samen ausstreut.

So viel bekannt ist, wird der Stinkasant von den hiesigen Eingebornen nicht gesammelt, da es zu wenig lohnend und wegen des Wassermangels mit grossen Mühen und Entbehrungen verknüpft ist. Am Fusse des Gebirges, wo das 
Wasser häufiger ist, bestehen zwar Ansiedelungen, sogar Städtchen, doch hier kommt die Pflanze nie vor, sondern nur in den trockensten, wasserärmsten Stellen, wo fast Nichts mehr gedeiht. (Pharmaceut. Zeitschrift für Russl. X. 738., Jahrb. für Pharmacic. Bd. XXXVII. Heft 4.).

C. Schulze.

\section{Zoologie und Physiologie.}

\section{Nutzen der Fische als Nahrungsmittel.}

Fische sind nach Agassiz ein Nahrungsmittel, das unsern Organismus, besonders nach geistigen Anstrengungen, erfrischt. Kein anderes ersetzt so vollständig die Verluste, welche das Gehirn durch die geistige Arbeit erleidet. Man weiss, dass das Fleisch der Fische eine grosse Menge Phosphor enthält, ein Element, das für die Gesundheit und Entwicklung des Gehirns durchaus nothwendig ist. Allerdings kann der Genuss von Fischen einen Idioten nicht in einen Gelehrten verwandeln, aher dennoch kann derselbe für die Verrichtungen des Gehirns sehr nützlich sein. (Aus der Natur. 1870.). 